\title{
Graves víctimas de la violencia domestica: un desafio para los adolescentes
}

\author{
Salcedo-Barrientos Dora ${ }^{1}$, Orchiucci-Miura Paula ${ }^{2}$, Marina Gemma ${ }^{3}$, Almeida-Silva Bruna ${ }^{3}$, \\ Tardivo- de La Plata Leila ${ }^{4}$
}

\section{RESUMEN}

Este estudio es parte de un proyecto más amplio titulado «Estudio de la violencia intra familiar contra las adolescentes embarazadas se reunieron en una Unidad Básica de la Zona Este de São Paulo: Bases para la intervención».(1) Objetivo: describir el perfil socio-demográfico de los adolescentes que forman parte del área de cobertura de una Unidad Básica de Salud ubicado en la zona este de São Paulo, así como identificar sus fortalezas y vulnerabilidades que enfrentan situaciones de violencia. Material y métodos: se realizó un con enfoque prospectivo, descriptivo y exploratorio, cualitativo y cuantitativo. Sostenidos por Praxis Intervención Teoría de Enfermería de Salud Pública - TIPESC (2), se desarrolló con 10 adolescentes embarazadas que son parte del Programa de Salud de la Familia y viven en la zona este de São Paulo. Los datos fueron analizados de acuerdo a las recomendaciones propuestas por el Wasteland epidemiológica literatura (1990) (3) y tardía y Pinto Junior (2010) (4), y el análisis del discurso de los temas contenidos en las entrevistas analizadas realizadas según Fiorin (2005) (5). Resultados: entre los principales resultados empíricos que presentamos cinco categorías: a) la invisibilidad de la violencia en la vida cotidiana, b) el embarazo como posibilidad de fortalecer el crecimiento y empoderamiento social c) la exclusión de los futuros padres durante el embarazo y el parto, d) fortalecimiento la familia de bonos y soporte de red consolidada e) la falta de confianza en los profesionales de la salud. Conclusiones: por lo tanto, este estudio contribuye al debate sobre las prácticas de salud más eficaz y eficiente orientada a satisfacer las adolescentes embarazadas víctimas de violencia intra familiar.

Palabras clave: el embarazo adolescente, la violencia intra familiar, tiene en la salud.Perú. (Fuente DeCs BIREME).

\section{Hemoglobin concentration and use of basic iron supplement during pregnancy and childbirth}

\begin{abstract}
This study is part of a larger project entitled «Study of intra familiar violence against pregnant teens met in a Basic Unit of the East Zone of São Paulo : Basis for intervention». (1) Objective: To describe the socio-demographic profile of adolescents who are part of the coverage area of a Basic Health Unit located in the East Zone of São Paulo, as well as identify their strengths and vulnerabilities facing situations of violence. Materials and Methods: This was a prospective, descriptive and exploratory, using qualitative and quantitative approach. Sustained by Praxis Intervention Theory of Public Health Nursing - TIPESC (2), was developed with 10 pregnant teenagers who are part of the Family Health Program and live in the East Zone of São Paulo . Data were analyzed according to the recommendations
\end{abstract}

\footnotetext{
Enfermeira. Doutora em Enfermagem. Psicodramatista - Sócio Educacional. Docente do Curso de Obstetrícia da Escola de Artes, Ciências e Humanidades da Universidade de São Paulo (EACH- USP). Pesquisadora do Grupo de Pesquisa Bases conceituais e metodológicas da enfermagem em saúde coletiva São Paulo (EEUSP). Líder do Grupo de Pesquisa «Mulher \& Saúde: Violência doméstica no período gravídico - puerperal» (EACH-USP)

2. Psicóloga. Doutora em Psicologia Clínica (PUC-SP). Pesquisadora do Grupo de Pesquisa Mulher \& Saúde: Violência doméstica no período gravídico - puerperal.

3. Discente do Curso de Obstetrícia da USP. Pesquisadora do Grupo de Pesquisa «Mulher \& Saúde: Violência doméstica no período gravídico puerperal»

4. Coordenadora do Laboratório de Saúde Mental e Psicologia Clínica Social (APOIAR), Professora Associada do Instituto de Psicologia da USP.
} 
suggested by the epidemiological literature Wasteland (1990) (3) and Belated\& Pinto Junior (2010) (4), and discourse analysis of the themes contained in the analyzed interviews conducted according Fiorin (2005) (5). Results:Among the main results, we present empirical five categories : a) the invisibility of violence in everyday life, b) the pregnancy as possibility of strengthening growth and social empowerment c) the exclusion of expectant fathers during pregnancy and childbirth, d) strengthening the bond family and support network consolidated e) lack of trust in health professionals. Conclusions: Therefore, this study contributes to the debate on health practices more effective and efficient geared to meet pregnant teenagers intra familiar violence victims. Keywords: Teenager pregnancy; intra familiar violence; needs in health.

Key words: Teenager pregnancy; intra familiar violence; needs in health. Brazil (Source DeCs BIREME).

\section{Grávidas vítimas de violência doméstica: um desafio para as adolescentes}

\section{RESUMO}

O presente estudo é parte de um projeto maior intitulado «Estudo da violência doméstica contra adolescentes grávidas atendidas em uma Unidade Básica da Zona Leste de São Paulo: Bases para intervenção» (1). Objetivo: Descrever o perfil sócio-demográfico das adolescentes que fazem parte da área de abrangência de uma Unidade Básica de Saúde localizada na Zona Leste de São Paulo, bem como identificar suas potencialidades e vulnerabilidades diante situações de violência. Materiais e Métodos: Trata-se de um estudo prospectivo, descritivo e exploratório, que utiliza abordagem qualitativa e quantitativa. Sustentado pela Teoria de Intervenção Práxica da Enfermagem em Saúde Pública - TIPESC (2) foi desenvolvido junto a 10 adolescentes grávidas, que fazem parte do Programa Estratégia Saúde da Família e vivem na Zona Leste de São Paulo. Os dados foram analisados de acordo com as recomendações sugeridas pela literatura epidemiológica Agreste (1990) (3) e Tardivo \& Pinto Junior (2010) (4), e a análise do discurso dos temas contidos nas entrevistas analisadas de acordo com Fiorin (2005) (5). Resultados: Entre os principais resultados, apresentam-se cinco categorias empíricas: a) a invisibilidade da violência na vida cotidiana, b) a gravidez como crescimento e fortalecimento c) a exclusão de futuros pais durante a gravidez e o parto; d) fortalecimento do vínculo familiar e a rede de apoio consolidada; e) falta de confiança nos profissionais de saúde. Conclusões: Portanto, este estudo contribui para a reflexão sobre práticas de saúde mais eficazes e eficientes voltadas para atender as adolescentes grávidas vítimas de violência doméstica.

Palavras chave: gravidez na adolescência; Violência doméstica; Necessidades em Saúde. Brasil. (Fuente DeCs BIREME).

\section{INTRODUÇÃO}

O presente estudo se insere como parte das ações de um projeto maior intitulado «Estudo da violência doméstica contra adolescentes grávidas atendidas em uma Unidade Básica da Zona Leste de São Paulo: Bases para intervenção» (1), cujo objetivo central foi diagnosticar casos de violência e compreender a experiência de violência doméstica vivenciada pelas adolescentes grávidas, que frequentam esta Unidade Básica.

A gravidez na adolescência deve ser analisada e refletida do ponto de vista social e psicológico. Observa-se uma diminuição de mães adolescentes nas classes de renda mais altas, mas nas classes de baixa renda o número de mães adolescentes continua crescendo. Do ponto de vista da escolaridade, a classe social também é relevante, pois o número de mães adolescentes que frequentam a escola é menor entre as que pertencem à classe social mais baixa (menos de 30\%). É também nesse nível socioeconômico que se encontram uma maior quantidade de mães adolescentes, que não exercem nenhuma atividade remunerada (6).

Um estudo sobre as relações familiares de mães adolescentes de baixa renda demonstra que muitas vezes a gravidez esteve associada a uma forma de lidar com a dificuldade na relação com a família de origem, como 
sentimentos de solidão, incompreensão e necessidade de atenção e cuidado. Em outros casos foi referida a gravidez como um meio de sair deste núcleo familiar de origem (7).

Oliveira (1999) (8) encontrou entre mães adolescentes de baixa renda vivências relevantes, como privação material e afetiva, conflitos com a educação formal ou mesmo evasão escolar e dificuldades na dinâmica familiar. Do ponto de vista psicodinâmico, Deutsch (1967) (9) coloca que a gravidez precoce poderia ser uma atuação relacionada a uma fixação precoce e primitiva à mãe. Ela entende que a menina frente à exigência de amadurecimento, buscou reviver a união mãe-filha por meio de uma gestação.

Como esse estudo aborda mães adolescentes vítimas de violência doméstica, se pode colocar que, das violências interpessoais, a cometida pelo homem contra a mulher ainda é considerada um dos maiores problemas mundiais, persistindo como uma violação dos direitos humanos, um impedimento na conquista da igualdade de gênero e um grave problema de saúde pública, visto que afeta profundamente a integridade física e a saúde mental das vítimas (10).

Segundo Durant (2006) (11), estatísticas epidemiológicas confirmam que $60 \%$ das mulheres grávidas foram vítimas de algum tipo de violência doméstica por parceiro íntimo durante o casamento, sendo que $20 \%$ delas sofreram violência física e psicológica grave - soco, queimaduras, ou ameaça de uso de arma - durante a gravidez.

Dentre as inúmeras transformações vivenciadas na adolescência, as relacionadas ao corpo estão entre as mais intensas e importantes, visto que a adolescente encontrase diante da possibilidade de usufruir de uma sexualidade adulta, experimentando novas maneiras de se relacionar com o corpo e com o outro (12).

A descoberta da sexualidade manifesta-se, geralmente, por meio de práticas sexuais desprotegidas, que podem estar associadas à falta de informação, de comunicação com os familiares e/ou adultos, entre outros motivos que acabam por expor os jovens a contextos vulneráveis, principalmente no que se refere às doenças sexualmente transmissíveis e gravidez indesejada (12).

Moreira et al (2008) (13) apontam que são poucas as famílias que aceitam a gravidez na adolescência e lidam com compreensão e afeto com o ocorrido. O nãoenfrentamento adequado destes conflitos, por parte dos familiares e/ou parceiros, pode levar a um estresse e resultar em atritos físicos e verbais. Dessa forma, a própria gestação pode ser uma porta de entrada para perpetuação de situações de violência doméstica.

Diante do exposto, este estudo teve como objetivo descrever o perfil sócio-demográfico das adolescentes que fazem parte da área de abrangência de uma Unidade Básica de Saúde localizada na Zona Leste de São Paulo, bem como identificar as potencialidades e vulnerabilidades das adolescentes grávidas diante de situações de violência doméstica.

\section{MATERIAIS E METÓDOS}

Trata-se de um estudo prospectivo, descritivo e exploratório, utilizando a abordagem quanti-qualitativa, com intuito de identificar as situações de violência doméstica vivenciada pelas adolescentes grávidas, que frequentam um posto de saúde na zona leste de São Paulo. Foi sustentado pela Teoria de Intervenção Práxica da Enfermagem em Saúde Coletiva - TIPESC (2), a qual adota a concepção de determinação social do processo saúde-doença como teoria interpretativa dos fenômenos e a intervenção sistematizada e dinâmica na realidade das adolescentes grávidas.

A coleta das informações foi feita por meio de entrevista semi-estruturada junto a 10 adolescentes grávidas, que fazem parte do Programa Estratégia de Saúde da Família de uma Unidade Básica de Saúde da Zona Leste de São Paulo.

Todos os responsáveis pelas adolescentes participantes assinaram o Termo de Consentimento e todas as adolescentes assinaram o Termo de Assentimento. Todos os preceitos éticos foram observados e o estudo foi aprovado pelo Comitê de Ética e Pesquisa da Secretaria de Saúde do Município de São Paulo (Parecer 329/11 CAAE: 0071.0.162.000-11).

Os dados foram analisados segundo as recomendações da literatura epidemiológica sugeridos por Agreste (1990) (3) e Tardivo \& Pinto Junior (2010) (4), e a Análise de Discurso dos temas contidos nos depoimentos foram analisados segundo Fiorin (2005) (5).

\section{RESULTADOS}

Neste estudo, o perfil de produção e reprodução social das adolescentes permitiu evidenciar: $80 \%$ das participantes se identificaram como solteira; escolaridade média de 
seis anos; $(70 \%)$ procedentes de São Paulo; cor autodeclarada: branca (50\%), parda (30\%), negra (10\%); 90\% desempregadas, dependentes financeiramente dos pais. Os discursos das adolescentes grávidas nas entrevistas foram reveladores como é possível ser evidenciado nas cinco categorias empíricas identificadas:

\section{Invisibilidade da Violência na Vida Cotidiana}

Dentre as 10 adolescentes entrevistadas, seis fizeram menção à violência. Duas adolescentes relataram que as situações de violência estavam relacionadas à gestação, sendo que, para uma das jovens, estas iniciaram após a confirmação da gravidez e, para a outra, os conflitos familiares já existiam, mas acentuaram-se após a gestação.

Em ambos os casos, houve agressões psicológicas e/ou morais que causaram impactos psíquicos e emocionais na vida das jovens. Isso pode ser observado por meio dos fragmentos de falas, carregados de expressões de indignação, angústia, raiva e/ou tristeza diante das situações de violência vivenciadas. Nos dois relatos, a violência foi perpetuada por pessoas íntimas da jovem, sendo em um caso pelo companheiro e sogra e, no outro, pela família do companheiro.

«(...)... Não agrediu, é... Como é que fala? Não fisicamente, verbalmente! (...) Quando eu descobri que tava grávida ela me expulsou de casa. Vim morar sozinha e tive que sustentar sozinha. E bancar ainda o meu enxoval sozinha! (...) ele foi mais a favor dela. Ele não ficou contra, não! Ele ficou contra mim e a favor dela! E também me agrediu! Minha gravidez de saúde foi bem, só que na parte sentimental da história foi... não foi fácil, não!» (E4).

"Teve vez que ela (sogra) chegou a me xingar eu não falei nada! Eu fiquei calada! (...) Vou ficar calada porque ela é mais velha e eu vou respeitar ela! Mas da próxima... Não abri minha boca, deixei ela me xingar. Mas dói! Dói!»(E5).

Mesmo diante destas situações, ambas participantes não identificavam estas experiências como violência, o que nos remete à invisibilidade acerca do tema, em que, devido ao contexto histórico, social e cultural da violência, as situações dificilmente são identificadas, visto que são naturalizadas pelas próprias pessoas, que as vivenciam.

«Eu não sei que nome dar a essa situação, não. Tantas coisa que... não sei que nome eu daria, não. Acho que não, violência não. Ah, é sem explicação...» (E4).
«Isso tudo me dá raiva. Ai, eu não sei! Sinceramente. Porque é ruim, é chato! Eu nunca vi uma situação dessa, nunca!» (E5).

Três adolescentes demonstraram ser vulneráveis a situações de violência devido às relações de poder advindas das questões de gênero. Em dois destes casos, a vulnerabilidade parece estar associada a conflitos na relação com o companheiro e, no terceiro, a conflitos na relação familiar (irmão).

«Depois de um ano a gente começou a brigar bastante, mas só briga de boca. Só de discussão. Discussão, discussão... Nunca chegou a baixaria de um xingar o outro assim de palavrão. Só de discussão!(...)Mas de bater assim, de brigar, nunca! Sempre um respeitou o outro» (E2).

«No geral, ele é uma pessoa boa, mas a gente briga mais por que ele bebe. Depois que ele bebe, ele fica alterado, faz brincadeiras de mau gosto, não só comigo, mas com a familia dele também. Ele sai e chega de madrugada, me deixa sozinha!» (E10).

«Ele pegou os meus trabalhos, eu fiz oito trabalhos! Ele rasgou tudinho meus trabalhos. Aquilo ali... Eu quebrei o aquário, eu quebrei (risos)...» (E1).

Apenas uma das participantes fez menção à violência social, relatando episódios de maus tratos e abandono de menor, observados em sua comunidade.

"Acho que eu teria medo de alguém maltratar. De acontecer alguma coisa.. Ai eu fico com medo. Não gosto, não. Ainda mais por ser novinho. Já vi maltratar criança de um ano, ai deixar na rua eu tenho medo. Eu já vi pai, mãe, uns que cuidava deixa na rua.. É. Aí eu fico com medo, dai por isso que eu vou cuidar» (E7).

\section{A Gravidez como Crescimento e Fortalecimento}

Com as modificações e particularidades da gravidez e da adolescência, é frequente a existência de sentimentos e atitudes ambivalentes, que podem gerar conflitos e questionamentos, visto que as mudanças na identidade e no novo papel social promovem a necessidade de reestruturação e reajustamento (13).

Nos resultados da pesquisa, este fato foi identificado em diversos fragmentos de fala. Praticamente todas as participantes não planejaram a gravidez, porém, de uma forma 
geral, contemplavam a ideia de maternidade em algum momento no futuro. Contudo, frente à responsabilidade advinda de uma gestação precoce, percebe-se que elas vêm e vão entre o comportamento de ser adolescente e ser adulto, o que gera bastante incerteza e torna difícil a mensuração das conseqüências do que é ter um filho.

"A minha gravidez aconteceu. Ah, quando eu fiquei sabendo eu fiquei em estado de choque, né?(...) Eu nunca pensei que podia ficar grávida com 14 anos.. Esperava ficar grávida só com 28 anos»(E2).

"Quando eu descobri que tava grávida foi ruim. Porque eu não pensava em ter filho agora. Quando eu engravidei já tava com 18 anos. E eu não queria engravidar» (E6).

«Nessa gravidez eu me senti um pouco confusa porque eu não sabia como ia ser a vida assim com filho. Eu pensava que ia ser ruim, que eu não ia... que eu não ia conseguir cuidar dele» (E6).

«Já sonhei que não tava grávida várias vezes, $e$ quando eu acordo é normal. O que eu senti? Ah, não sei. Não sei dizer, foi de alegria. Frustração em nenhum momento» (E7).

De forma geral, reconhecer a responsabilidade inevitável da maternidade faz com que as jovens apresentem comportamentos que objetivam evitar prejuízos para elas e para os seus bebês. A noção de responsabilidade, identificada nessa pesquisa, está associada ao abandono de atividades em que elas tinham diversão e interação social.

A grande maioria das participantes referiu como «mudanças após a gestação» o fato de ficar mais em casa, não saindo tanto com os amigos e melhorando o relacionamento com a família. Algumas atribuem a este fato certa sensação de estranheza, porém, aparentemente, isso não se configura como um sentimento de perda, visto que, ao relatarem, elas não apresentaram expressões de tristeza (choro, silêncio, mudança no tom de voz), como é possível identificar nas falas a seguir.

«Queria poder continuar me divertindo, sabe? Agora eu fiquei presa praticamente. (...) Agora eu tô me acostumando mais, já me acostumei, já até falo com ela dentro da barriga (risos)» (E5).

«Eu saia antes, mas agora não dá vontade mais não. Todo mundo fica falando pra «mim» sair, mas não dá vontade não» (E8).
«Eu sinto que mudei bastante nessa gravidez, por que antes eu vivia na rua, só gostava de sair. Agora, não tenho tanta vontade pra isso. Eu era bagunceira, aquelas meninas tranqueiras! Agora eu mudei bastante. Eu fico em casa, não saio mais. Também não tem como, né?» (E10).

\section{A Exclusão dos Futuros Pais durante a Gravidez e o Parto}

A literatura científica a respeito da gravidez na adolescência é vasta no que se refere às questões relacionadas à figura feminina, no entanto, quando se trata da figura masculina, o papel do parceiro é frequentemente apresentado de maneira indireta, seja por índices de mães solteiras ou pelo apontamento da sua ausência como um fator estressante para a gestante (14).

Apesar da maioria das participantes estar em um relacionamento com o parceiro no momento da pesquisa, as expressões de dependência ao companheiro estiveram mais relacionadas à dependência financeira para a criação dos filhos, seguido da dependência emocional. Apenas três das adolescentes apresentavam relações conflituosas e estavam separadas do companheiro.

O envolvimento do companheiro é mais requisitado no que se refere ao apoio financeiro para a criação dos filhos, sendo o relacionamento duradouro do casal uma preocupação secundária. Isto remete à questão social e histórica da maternidade, em que o homem, geralmente, configura-se como o provedor, cabendo à mulher a responsabilidade pela gestação e criação dos filhos.

Este fato é comprovado quando, na maioria dos discursos, se identificam expressões de que o companheiro assumiu e/ou ficou feliz com a gravidez, em oposição aos sentimentos ambivalentes experimentados pelas adolescentes, o que nos leva a crer que, apesar de todos os esforços nacionais e internacionais na busca pela equidade de gênero, os estereótipos feminino e masculino pré-definidos pela sociedade ainda estão fortemente presentes no comportamento dos indivíduos, inclusive no dos mais jovens.

"Porque, ele veio trazer dinheiro, né?! Eu não queria olhar pra cara dele (...)» (E1).

«O meu companheiro não ta comigo (...) Depois que eu fiquei grávida a gente se fala bem pouco, ele me liga pra saber do bebê... Mas é só assim (...) Ele falou que 
ia me ajudar a cuidar do meu filho» (E2).

«Ele queria. Faz tempo que ele queria. Tinha tempo que eu queria e tinha tempo que eu não queria»(E3).

«Eu não tenho medo do meu namorado ir embora, não... Se ele quiser ir, oxe, pode ir! Sustentando a filha dele..» (E5).

\section{Fortalecimento do Vínculo Familiar e Rede de Apoio Consolidada}

Todas as adolescentes relataram sobre a importância da relação familiar para o enfrentamento/adaptação à gestação, tanto no que se refere à aceitação da gravidez quanto ao auxílio para cuidar do filho. Na maioria dos discursos foi possível perceber que não houve conversas sobre a prevenção da gravidez e que, quando existiram, não ultrapassavam as barreiras da «advertência», no intuito de moldar o comportamento das adolescentes.

A existência e importância do suporte familiar foram expressivas entre as participantes. Mesmo que após um primeiro momento de crise - relacionados à preocupação quanto ao futuro das adolescentes, principalmente no que se refere à questão dos estudos, seguido pela preocupação com o envolvimento dos parceiros das jovens na criação do filho - as adolescentes foram acolhidas por suas famílias, contradizendo, assim, o comum discurso socialmente reproduzido de que a gravidez na adolescência tem influência das famílias disfuncionais. Vale ressaltar que as participantes apresentavam estruturas familiares diferentes, mas, no geral, contavam com o apoio material e afetivo das pessoas de sua rede social mais próxima e isso lhes proporcionava segurança para vivenciar a gestação de uma forma mais saudável.

Todas as adolescentes recorreram às suas famílias para se reestruturar e adaptar à gravidez, sendo que a figura materna esteve mais associada ao apoio emocional e a figura paterna ao apoio instrumental. No entanto, não se pode observar um padrão. Segundo os relatos das adolescentes, percebeu-se que estes apoios familiares foram fundamentais para o seu bem-estar, interferindo de forma positiva em suas vidas, o que reforça, portanto, a importância da rede social para a saúde física e emocional do indivíduo.

"Ah, quando eu fiquei sabendo (gravidez) eu fiquei em estado de choque, né? (...) Mas eu contei pra minha mãe, minha mãe não falou nada, sabe? Me apoiou» (E2).
"Minha sorte foi minha mãe e minhas tias do Maranhão que elas me ajudavam... Elas mandavam dinheiro pra comprar alguma coisa e tudo... e a minha patroa que me ajudou também!»(E4).

«Ai no comecinho eu já logo falei pros meus pais e fui tentando aceitar (a gravidez)» (E5).

«É, eu engravidei. Ah, foi que meus pais queriam me matar (risos) (...)Ah, eles já aceitaram. até me ajudam. Quando eu preciso de alguma coisa eles me ajudam» (E9).

«Meu pai reagiu muito normal, mas eu esperava o pior dele, porque eu esperava que ele fosse me mandar embora de casa (...) Antes de eu engravidar ele falava que se um dia eu aparecesse grávida dentro de casa ele me matava, e por isso eu fiquei assustada. Mas mesmo assim, meu pai foi sossegado, e hoje está feliz.»(E10).

\section{Falta de confiança nos Profissionais de Saúde}

$\mathrm{Na}$ pesquisa, oito participantes fizeram menção aos atendimentos oferecidos pelos serviços de saúde. Destas, quatro estavam satisfeitas com a assistência recebida, sendo que somente uma se queixou da reorganização das áreas do Programa Estratégia Saúde da Família, referindo gostar mais de seu antigo médico e enfermeira, pois eles a escutavam e lhe davam mais explicações e atenção, enfatizando, assim, a importância da valorização da «escuta», do papel da mulher como coparticipe e corresponsável pela assistência.

No que diz respeito aos conflitos, foi possível identificar fragmentos de fala no discurso de quatro participantes que se relacionam à falta de vínculo entre serviço de saúdepaciente. Todas referiram não comentar com os profissionais que as atendem na UBS questões mais pessoais, o que nos faz refletir sobre o predomínio do caráter biomédico durante os atendimentos, em que as questões sobre o contexto social e psicológico não costumam ser investigados e/ou a própria paciente as considera «íntima» para relatar durante as consultas.

«Eu não falo as coisas que acontecem comigo com o pessoal do posto, não. Eles nunca me perguntaram nada» (E1).

«Essa situação com o pai do bebê foi uma decisão minha. O pessoal do posto não ta sabendo... É uma coisa mais intima» (E2). 
"Meu médico teve que ser trocado aqui, porque teve que mudar. mudou as moças assim.. a agente comunitária era de uma área, passou pra outra, ai mudou o médico também. Eu gostava mais do antigo, porque ele era bom, conversava» (E3).

«Não falei nada com ninguém aqui do posto, não, porque aqui também... A maioria que trabalha lá dentro é daqui de dentro da comunidade e essa conversa... Nunca chega do jeito que é, né? Então um passa pro outro... principalmente entre as agentes! Que todo mundo aqui no bairro comenta! Entendeu? Então pra não ter fofoca, intriga, colocar lenha na fogueira, então é melhor essas coisas não falar, né?»(E4).

«Eu não falei nada disso com os profissionais aqui do posto de saúde, não. É a primeira vez que eu falo disso com uma pessoa do posto (pesquisadoras)» (E5).

Vale ressaltar que dentre estas quatro participantes, três foram vítimas e/ou são vulneráveis a situações de violência doméstica, tornando esta crise de confiança entre profissional-paciente ainda mais alarmante, uma vez que os profissionais de saúde têm um papel importante para a quebra do silêncio e o próprio ciclo da violência, principalmente no que se refere à identificação, apoio psicossocial e encaminhamento dos casos.

No que diz respeito às quatro participantes que não apresentaram queixas para com a assistência recebida, pode-se pensar que, talvez, essa aparente satisfação se deva ao fato de que muitas das posturas e práticas dos profissionais de saúde consideradas inadequadas são incorporadas pelos pacientes, que, em vários momentos, se adaptam ao comportamento que as equipes esperam deles, reproduzindo os discursos das mesmas e apresentando uma participação passiva durante a assistência (15).

\section{DISCUSSÃO}

O presente estudo demonstrou que a violência doméstica aparece de forma naturalizada pelas adolescentes que vivenciaram situações de violência, visto que não definem suas vivências desta maneira. Esta forma da percepção alienada da violência aumenta a vulnerabilidade e o risco de vida destas adolescentes e de seus bebês.

Igualmente, pôde-se perceber que as adolescentes, durante o processo gestacional, demonstram grandes modificações, que vão desde a não aceitação da gravidez à necessidade de desenvolver a responsabilidade inevitável da maternidade.
Outro resultado observado refere-se a pouca importância atribuída aos futuros pais dos bebês pelas adolescentes. A maioria delas restringe esta importância apenas ao apoio financeiro e o desenvolvimento das relações afetivas do casal considera-se um determinante prioritário a serem refletidos e fortalecidos em posteriores intervenções.

O apoio da família das adolescentes se mostrou fundamental no processo de aceitação e desenvolvimento da responsabilidade da adolescente pela maternidade. Além disso, o apoio e o acolhimento da família fortalecem e minimizam a vulnerabilidade de possíveis ocorrências de situações de violência.

Outro aspecto que pôde ser percebido, é que as adolescentes grávidas apontam para a necessidade de profissionais de saúde que acolham e escutem, ou seja, que estabeleçam vínculos para que elas possam confiar na relação e, então, falar sobre as intimidades das suas relações, principalmente, sobre as situações de violência doméstica vivenciadas.

Desta forma, esta pesquisa possibilitou uma reflexão e análise sobre as vivências, experiências e necessidades em saúde das adolescentes grávidas com seus familiares, companheiros e profissionais de saúde, contribuindo para a elaboração de práticas de saúde mais eficazes voltadas ao atendimento destas adolescentes vítimas de violência doméstica, bem como para subsidiar elementos metodológicos e repensar na inovação de novos instrumentos de enfrentamento deste fenômeno considerando estas demandas sociais na Atenção Básica.

\section{REFERÊNCIAS BIBLIOGRÁFICAS}

1. Salcedo-Barrientos DM. Estudo de Violência Doméstica contra Adolescentes Grávidas Atendidas em uma unidade básica na zona leste de São Paulo: Bases para Intervenção. Projeto de Pesquisa. Curso de Obstetrícia. Universidade de São Paulo. 2011.

2. Egry EY. Saúde coletiva: construindo um novo método em enfermagem. São Paulo: Ícone, 1996.

3. Agreste A. Categorical data analysis. New York: Willey, 1990.

4. Tardivo LSLPC, Pinto Junior AA. Inventário de frases no diagnóstico de violência doméstica contra crianças e adolescentes. $1^{\mathrm{a}}$ ed. São Paulo: Vetor, 2010.

5. Fiorin JL. Elementos de análise do discurso. São Paulo: Contexto, 2005.

6. Novellino MSF. Um estudo sobre as mães adolescentes brasileiras. Physis (Rio J.) [Internet]. 
2011 [acesso em 20 Set 2012]; 21(1):299-318. Disponível em : http://www.scielo.br/pdf/physis/v21n1/ v21n1a17.pdf

7. Falcão DVS, Salomão NMR. Mães adolescentes de baixa renda: um estudo sobre as relações familiares. Arq. bras. psicol. [Internet]. Dez 2006 [citado 20 Set 2012]; 58(2): 11-23. Disponível em: http:// pepsic.bvsalud.org/pdf/arbp/v58n2/v58n2a03.pdf

8. Oliveira NR. Perfis de mães adolescentes: Estudo Psicossocial de adolescentes usuárias de um Serviço Público de Pré Natal e maternidade. [tese] São Paulo: Instituto de Psicologia, Universidade de São Paulo; 1999.

9. Deutsch H. Problemas Psicológicos da Adolescência. Com ênfase especial na formação de grupos. Trad.: Edmond Jorge. $3^{\mathrm{a}}$ ed. Rio de Janeiro: Zahar Editores. 1983 (1967). $125 \mathrm{p}$.

10. Lima DC, Buchele F, Climaco DA. Homens, gênero e violência contra a mulher. Saúde soc [Internet]. Jun 2008 [acesso em 19 Set 2012]; 17(2):69-81. Disponível em: http://www.scielo.br/pdf/sausoc/ v17n2/08.pdf

11. Durant JG. Gestação e violência: estudo com usuárias de serviços públicos de saúde da grande São Paulo [tese]. São Paulo: Faculdade de Medicina, Universidade de São Paulo; 2006.

12. Camargo EAI, Ferrari RAP. Adolescentes: conhecimentos sobre sexualidade antes e após a participação em oficinas de prevenção. Ciênc. Saúde colet [Internet]. Jun 2009 [acesso em 10 Dez 2011];
14(3): 937-946. Disponível em: http:// www.scielosp.org/pdf/csc/v14n3/30.pdf

13. Moreira TMM, Viana DS, Queiroz MVO, Jorge MSB. Conflitos vivenciados pelas adolescentes com a descoberta da gravidez. Rev. esc. enferm. USP [Internet]. Jun 2008 [acesso em 10 Dez 2011]; 42(2): 312-320. Disponível em: http://www.scielo.br/pdf/ reeusp/v42n2/a14.pdf

14. Gonçalves SD, Parada CMGL, Bertoncello NMF. Percepção de mães adolescentes acerca da participação paterna na gravidez, nascimento e criação do filho. Rev. esc. enferm. USP [Internet]. São Paulo, v. 35, n. 4, Dec. 2001 [acessos em 30 Jun 2012]. Disponível em: http://www.scielo.br/pdf/ reeusp/v35n4/v35n4a13.pdf

15. Aguiar JM. Violência institucional em maternidades públicas: hostilidade ao invés de acolhimento como uma questão de gênero [tese] São Paulo: Faculdade de Medicina da Universidade de São Paulo. 2010.

\section{Correspondencia}

Dora Salcedo Barrientos

Universidade de São Paulo (EACH- USP). São Paulo. Brasil.

Correo electrónico: dorabarrientos@usp.br

Pagina Web: http://www.mulheresaude.com.br/

Forma de citar este artículo: Salcedo-Barrientos D, OrchiucciMiura P, Gemma M, Almeida-Silva B, de la Plata-CuryTardivo L. Graves víctimas de la violencia domestica: un desafio para los adolescentes. Rev enferm Herediana. 2012;5(2):125-132. 